\title{
Signal Enhancement of Hydroquinone and Catechol on Their Simultaneous Determination
}

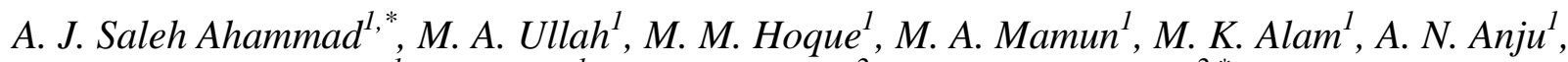 \\ M. N. Islam Mozumder ${ }^{1}$, R. Karim ${ }^{1}$, Subrata Sarker ${ }^{2}$ and Dong Min Kim, ${ }^{2, *}$ \\ ${ }^{1}$ Department of Chemistry, Jagannath University, Dhaka 1100, Bangladesh \\ ${ }^{2}$ Department of Materials Science and Engineering, Hongik University, Sejong 300116, South Korea \\ *E-mail: ajsahammad@chem.jnu.ac.bd,dmkim@hongik.ac.kr
}

doi: $10.20964 / 2017.08 .64$

Received: 1 February 2017 / Accepted: 11 June 2017 / Published: 12 July 2017

\begin{abstract}
An activated glassy carbon electrode (GCE), prepared by applying a constant oxidation potential, can simultaneously determine hydroquinone (HQ) and catechol (CC). Here, we report on the modification of the electrochemical activation process of the GCE by applying a constant reduction potential preceded by the application of constant oxidation potential. The GCE activated through two-step electrochemical activation enhanced peak currents of HQ and CC compared to that activated only at a constant oxidation potential. The redox responses from the mixture of HQ and CC were easily resolved at the improved activated GCE. The peak potential separation of $110 \mathrm{mV}$ was large enough for the simultaneous determination of $\mathrm{HQ}$ and $\mathrm{CC}$. The oxidation peak currents of $\mathrm{HQ}$ and $\mathrm{CC}$ were linear over the range from 1 to $200 \mu \mathrm{M}$ with the detection limits $(\mathrm{S} / \mathrm{N}=3)$ of 37 and $26 \mathrm{nM}$, respectively.
\end{abstract}

Keywords: Hydroquinone, Catechol, Activated glassy carbon electrode, Signal enhancement.

\section{FULL TEXT}

(C) 2017 The Authors. Published by ESG (www.electrochemsci.org). This article is an open access article distributed under the terms and conditions of the Creative Commons Attribution license (http://creativecommons.org/licenses/by/4.0/). 